\title{
Reseña \\ weren \\ Lamas, M. (2018). Acoso. ¿Denuncia legítima o victimización? Fondo de Cultura Económica, 182 pp. (Colec. Cenzaontle)
}

\author{
Claudia Esthela Espinoza ${ }^{1}$
}

Fecha de recepción: 4 de enero de 2020

Fecha de aceptación: 28 de mayo de 2020 n esta reseña se comenta el libro Acoso. ¿Denuncia legítima o victimización? publicado dentro de la colección Centzontle, del Fondo de Cultura Económica. A partir de la que refiere como urgencia ética para afrontar la grave situación de acoso en nuestro país, Marta Lamas se interesa por dilucidar acerca del discurso social hegemónico y los efectos negativos de poder ejercidos mediante la retórica de este problema. La obra se centra en la reciente visibilización del acoso, se destaca el movimiento de denuncia \#Me too en los Estados Unidos de Norteamérica y que en México se diera a conocer a través de redes sociales con el hashtag \#Mi primer acoso. Se analiza también una de las réplicas hacia \#Me too, la misiva firmada por un grupo de actrices, académicas y activistas francesas, y que se tituló: $<<$ Defendemos una libertad de importunar, indispensable a la libertad sexual >> (la traducción completa al español de este posicionamiento se incluye al final del texto). Su autora sostiene que aunque los contextos y procesos en Francia y Estados Unidos son distintos a los de México, la división feminista sobre las perspectivas de interpretación del acoso es un debate que también concierne a nuestro país, en particular por sus efectos políticos y jurídicos de poder.

Provocador y polémico desde su título, es una invitación al debate de los significados dominantes del acoso, reflexión que esta antropóloga percibe como fundamental por las consecuencias discursivas de reducir en el significante <<acoso >> "la complejidad de un contexto violento, desigual y explotador." Bajo esta premisa, Lamas argumenta que no todas las denuncias pueden ser consideradas acoso sexual, pues algunas mujeres nombran así diversos usos y costumbres culturales como piropos o prácticas quid pro quo (intercambio de un favor por otro). El término sirve a esas mujeres para canalizar sus malestares e indignación por ciertas prácticas machistas, violentas o discriminatorias que padecen en múltiples contextos, sin que tales prácticas necesariamente constituyan acoso sexual. Insiste en la apremiante necesidad ética de alentar desde el feminismo -en diálogo con sus aliados- la discusión sobre discursos

1- Nacionalidad: Mexicana. Grado: Doctorado en Ciencias Sociales. Institución: Universidad de Sonora. (DORCID: http:// orcid.org/0000-0002-0045-178X. Correo electrónico: espinozaclaudia@hotmail.com 
y prácticas emancipadores, en especial para erradicar los que llama tropiezos, pasos en falso o errores dentro de ese movimiento.

El texto se organiza en siete capítulos, antecedidos de un prólogo donde la antropóloga explica sus pretensiones con su libro. En el primer capítulo, De la liberación sexual al miedo a la sexualidad, Lamas nos recuerda que durante los sesenta en la Unión Americana surgen diversos movimientos sociales, uno de ellos el de liberación de las mujeres; y que sus principales reivindicaciones fueron la liberación sexual y la lucha contra la violencia sexual. Nos menciona que en la década posterior diversos sectores del feminismo discreparían sobre los significados de la libertad sexual y violencia sexual, lo que conduciría a las Sex Wars o «guerras en torno a la sexualidad». La lucha contra el sexual harassment nace para esta teórica del encuentro de dos activismos: a) de derechos civiles que combatía la discriminación laboral y b) feminista que pedía erradicar la violencia sobre las mujeres. Lamas reconstruye ese contexto para señalar que las teorizaciones y el activismo contra el acoso -impulsado desde 1970 principalmente por las dominance feminists o feministas radicales norteamericanas- han influido de manera decisiva en cómo se entiende y actúa sobre el problema en aquel país y muchos otros, incluido México. La mirada feminista radical ve en el sistema legal un mecanismo para la pervivencia del dominio masculino; para Lamas esta visión radical difiere de la teoría jurídica crítica, pues en esta última aunque también se considera el potencial del derecho como dispositivo de dominación, se interesa por el conjunto de seres humanos, y no sólo por el colectivo de mujeres.

En el capítulo segundo, Violencia sexual y victimismo mujerista, Lamas destaca los avances del feminismo para visibilizar e incidir contra las violencias hacia las mujeres en México y el resto del mundo. Pasa revista a la literatura generada por diversas autoras feministas en el rubro de la violencia de género, así como postula la necesidad de cuestionar determinadas acciones para hacer visible y denunciar el acoso, las cuales pueden tener (y señala que de hecho han tenido) consecuencias injustas hacia algunos de los señalados por acoso. La autora se preocupa porque la estructura hegemónica histórica, social e institucionalmente específica de enunciados, categorías, creencias y términos, en otras palabras, el discurso dominante sobre el acoso colisiona con los derechos fundamentales y el debido proceso de los varones señalados, considera que en tal discurso se apuesta por su criminalización. Critica el mujerismo y victimismo, al primero lo define como una perspectiva desde la cual se asume que las mujeres poseen una esencia diferente e inherentemente mejor que la de los hombres, mientras que al segundo -a partir de las ideas de Elisabeth Badinter- lo concibe como categoría político-jurídica que instala a las mujeres en el rol de víctimas permanentes; el victimismo puede reconocerse en el discurso hegemónico del acoso según lo afirma Lamas. Siguiendo a Janet Halley, ella identifica como principal componente de ese discurso a la tríada analítica: inocencia de las mujeres/daño que sufren/inmunidad de los hombres. Argumenta que tal esquema ha sido clave en la edificación de parte considerable de la actual política feminista, en particular los discursos dominantes sobre violencia sexual; es una postura que contribuye a mantener una actitud no crítica hacia quienes son víctimas, a la vez que distorsiona sus reclamos legítimos por la reparación, ya que se mantienen a perpetuidad el lamento y la exigencia.

En el capítulo tercero, La epidemia de acoso en las universidades estadunidenses, el análisis del problema se traslada al ámbito universitario de los Estados Unidos de Norteamérica. Discurre acerca de dos fenómenos: a) el empoderamiento en la década de los ochenta por parte de estudiantes que denunciaron a profesores y compañeros de clases que las acosaban y b) el pánico sexual (término acuñado por Carol 
Vance), una variante del pánico moral (concepto de Cohen para designar la reacción social inadecuada frente a asuntos mínimos, conlleva un miedo desmedido por el peligro verdadero de que suceda lo temido). Este pánico sexual se caracteriza por la irracionalidad, el conservadurismo y su utilización para nombrar miedos irracionales hacia determinadas expresiones y prácticas sexuales. Lamas explica que los discursos extremistas de teóricas feministas como MacKinnon y Dworkin, donde la sexualidad masculina se interpreta como fuente de opresión para todas las mujeres en la sociedad y que por ello debe condenarse al colectivo de varones, han contribuido para generar un «pánico sexual» de tipo androfóbico, al que se añade la consigna conservadora que demanda mayor rigor del sistema judicial penal. Afirma que, quizá sin saberlo, el paradigma victimista del feminismo radical imbuido por ese pánico moral ha abonado en la consolidación del paradigma sexo-genérico conservador. Lamas se apoya en Katie Roiphe, estudiante feminista en Harvard que describe en un artículo el ambiente de temor y peligro prevalente en los ochenta ante la supuesta «epidemia» de violencia sexual en los campus, la autora explica que tanto feministas radicales como conservadores religiosos, fueron quienes a partir de denuncias sobre casos notorios de acoso, denunciaron esa epidemia en las universidades.

En el capítulo cuarto, La disputa cultural entre Francia y Estados Unidos, se retoman las ópticas sobre el acoso en los dos países. La primera visión se origina en el movimiento \#MeToo, una movilización que por virtud de la «americanización» ha tenido repercusiones globales; la americanización de la modernidad es la imposición de la tendencia principal de desarrollo de los Estados Unidos de Norteamérica sobre la vida económica, social y política del orbe. Tal influencia lleva a que Marta Lamas resalte los aportes del feminismo radical de esa nación como uno de los principales referentes analíticos en su libro. La segunda emerge desde Francia con el posicionamiento en respuesta a \#MeToo, esta perspectiva representa el deslinde y la denuncia al enjuiciamiento mediático y extremismo que nacen de asumir que es acoso cualquier requerimiento sexual. Para Lamas, el posicionamiento textualiza las profundas diferencias entre feministas galas y estadunidenses sobre cómo ha de entenderse y erradicarse el acoso. Argumenta que si bien el contexto francés es diferente al mexicano, el documento deja en claro que no todas las mujeres reaccionan del mismo modo ante requerimientos, insinuaciones o tocamientos sexuales.

En el capítulo quinto, La controversia en México, se analiza el proceso discursivo sobre el acoso a través del concepto de $<<$ americanización $>>$. La premisa es que las discusiones alentadas por el feminismo estadunidense han servido de marco a la lucha feminista en el planeta, y el movimiento mexicano ha sido influido también a nivel teórico y político por las ideas provenientes del país vecino acerca el acoso y su eliminación. De igual manera, Lamas nos pide tener en mente que la sociedad mexicana está imbuida de valores tradicionales de corte judeo-cristiano, por lo que a la sexualidad de las mujeres se atribuyen virtudes como recato, fidelidad, virginidad, entre otras; un horizonte como éste reduce la autonomía sexual de las mujeres y estigmatiza sus prácticas sexuales fuera del marco de $\langle<$ lo decente $>>$, es decir, aquellas que son ajenas a una relación sexo-afectiva estable. Dentro de este contexto de doble moral sexual, al término acoso se le asocian múltiples conductas que a diario sufren las mujeres: miradas insistentes, $<<$ propuestas indecorosas $>>$, groserías, silbidos, por mencionar sólo algunas. Precisa que semejantes expresiones son machistas, reconoce que pueden desgastar o irritar a las mujeres y que es importante erradicarlas, pero se cuestiona si desde el punto de vista político es correcto calificar a todos esos comportamientos como acoso; para ella esto implica reproducir el victimismo del discurso hegemónico, lo que evita llegar a la raíz del problema y dicha renuncia tiene desde luego efectos negativos. Prosigue su genealogía del 
acoso con la revisión de definiciones gramaticales de acoso y analiza los delitos sexuales previstos en códigos penales de algunas entidades federativas. Enfatiza que aunque eficaz y necesaria, la vía legal no es la única solución y que el cambio soñado ha de ser cultural, de cara a las serias deficiencias en acceso a la justicia para las víctimas de violencia de género y sexual en México.

En el capítulo sexto, ¿Guerra entre los sexos o conflicto de interés entre mujeres y hombres? se aborda el concepto de $<<$ residuo tolerado del abuso $>>$, acuñado por el teórico de los estudios jurídicos críticos Duncan Kennedy- para mostrar la importancia de discutir las pérdidas y ganancias para mujeres y hombres por la no eliminación del abuso sexual en la sociedad; este remanente corresponde a la parte del abuso sexual que queda impune. A partir de esta idea Lamas se pregunta qué ganaríamos unas y otros si dejásemos de depositar en las mujeres la responsabilidad por evitar los abusos. La autora explica que para Kennedy el abuso sexual instaura pautas culturales y representa un elemento estructurante en la edificación tanto de la sexualidad femenina como masculina; la noción del feminismo radical sobre la «erotización de la dominación» designa el hecho de que mujeres y varones se recrean con imágenes y experiencias de dominación de los segundos sobre las primeras. El conflicto de interés entre los sexos se agrava porque los hombres suelen tener el control de los procesos judiciales, las mujeres quedan en desventaja frente al sistema de justicia, el cual penaliza en general el abuso sexual contra ellas por parte de los hombres, a la vez que tolera una multiplicidad de variedades de abuso.

En el capítulo séptimo, La amnesia social, ese término se trae a colación para aludir a las dinámicas sociales y políticas que erosionan la memoria y hacen difícil entender problemas como el acoso. La autora nos explica, siguiendo a Jacoby, que esta forma de amnesia es una tendencia cultural presente en la sociedad moderna e implica el olvido -incluso en el ámbito académico- de los planteamientos psicoanalíticos (pulsión sexual, deseo y represión que permean los comportamientos humanos). Plantea que la amnesia social resulta funcional a la dinámica sociopolítica contemporánea porque difunde la idea de que todo es susceptible de ser conocido, al tiempo que desconoce rupturas y desplazamientos provocados por la actividad del inconsciente (fantasía, deseo o represión); y que ello sucede pese a que lo inconsciente permea la dimensión psíquica individual y social. La perspectiva de las dominance feminists junto con la amnesia social opera en el discurso sobre el acoso a modo de dispositivo que al tener como eje la «depravada» heterosexualidad de los hombres, supone olvidar cuanto se sabe respecto las complejidades y ambigüedades de las relaciones humanas, opaca también otros elementos presentes en las relaciones sexuales ya sean deseadas o no deseadas, por ejemplo: clase social, condición étnica, edad, orientación sexual, por nombrar algunos. El desconocimiento de esas distinciones se traduce en un desplazamiento del problema del campo social al de la sexualidad, con lo que se dejan de reconocer situaciones donde algunas diferencias sociales pueden ser más determinantes que la sexual. Lamas entonces argumenta que esto es un error analítico a la par que político, ya que la política sexual de las feministas radicales asimila valores patriarcales y estigmas judeocristianos; la interpretación sobre el conflicto entre mujeres y hombres es reduccionista, se estrechan las posibilidades de accionar político y se conforman con demandar un aparato que castigue (en forma desproporcionada) algunos comportamientos sexuales de los hombres, incluso conductas eróticas no agresivas.

El libro finaliza con un epílogo donde la antropóloga se interroga sobre lo que podría hacerse con la rabia generada ante la grave situación de hostigamiento, acoso y violencia sexual que de manera cotidiana padecen miles de mexicanas. Reflexiona acerca de la importancia de plantear una nueva terminología jurídica útil para afrontar la realidad social del problema, aquí propone el término $<<$ acoso social ma- 
chista $\gg>$ para nombrar y combatir las experiencias cotidianas que viven mayoritariamente las mujeres pero también hombres gays y personas trans en el espacio público. Sugiere que a las acciones para frenar estas violencias se sumen las de incentivar a que las mujeres aprendan a defenderse; también aborda la relevancia de trabajar en la violencia simbólica, como forma invisible de dominación (idea que retoma de Bourdieu), la cual impide su reconocimiento por quienes la padecen. Lamas sostiene que de hecho el victimismo prevalente en ciertos feminismos podría ser analizado como una forma de violencia simbólica, y que el enemigo principal no son los hombres (si bien aclara que muchos son parte del problema) pues la atroz violencia que ellos resienten actualmente es opacada por un discurso hegemónico sobre la gravedad de la violencia de género donde las mujeres son vistas como las únicas víctimas. Nos alienta a preguntarnos si el némesis acaso no son los procesos materiales y simbólicos del capitalismo neoliberal, configuradores de cambios en las relaciones entre mujeres y hombres, a la vez que reforzadores de políticas sexuales moralizadoras y represivas que actúan en las subjetividades de mujeres y hombres.

En términos globales, a través de este libro se plantea una discusión novedosa y necesaria, sobre todo en el contexto de violencias contra las mujeres que impera en el México actual. Destaca el uso que la autora hace de la teoría psicoanalítica feminista para introducir una discusión rigurosa, crítica y ordenada sobre múltiples significados del acoso, los matices de este término y sus implicaciones políticas y jurídicas. No obstante, un elemento ausente en sus planteamientos es la heterogeneidad del campo jurídico mexicano, un espacio social donde en efecto compiten significados punitivos sobre el acoso pero también están presentes significados provenientes de diversos agentes. Reconocer la diversidad de significados sobre el acoso en el campo jurídico nacional permitiría entender que el influjo en México de los significados de las dominance feministas debe contender con otros significados que múltiples agentes buscan imponer también, y que algunos significados pueden no replicar la triada analítica denunciada por Lamas, poniendo en entredicho por ejemplo la idea de inocencia de la víctima.

Se advierte que quedó pendiente también de explorarse el entrelazamiento del debate del acoso con otros como el de los derechos humanos, los derechos de las víctimas y de los procesados, discusiones relevantes a la luz del cambio de paradigma del sistema de justicia penal. En México transitamos hacia nuevas maneras de entender el papel de quienes ha sido víctimas de delitos en los procesos de justicia, las víctimas son sujetos que hasta hace poco tiempo ni siquiera aparecían en los textos legales y apenas si eran nombradas, con lo que sus posibilidades de reparación vía judicial eran mínimas, si no es que nulas en muchos casos.

Estamos frente a nuevas perspectivas respecto a cómo se entiende la justicia, y que probablemente influirán en cómo se atienden y sancionan los delitos de acoso sexual y hostigamiento sexual. Si bien, el debido proceso ocupa un papel relevante en el texto de Lamas (concepto que no define), la autora es omisa en cuanto a la historicidad de esta noción. Si seguimos su propuesta analítica, un debate sobre los significados del acoso exigiría de igual manera reconstruir la genealogía de conceptos como el debido proceso y la presunción de inocencia. Ello es crucial porque, como dice Lamas, el discurso hegemónico del acoso avanza una suerte de justicia privada -representada en las estrategias de denuncia social por parte del feminismo radical- que amenaza con arraigarse en México; recordemos encima que el personal ministerial y judicial de nuestro país se caracteriza por su ineficiencia y escasa preparación para afrontar el problema con la sensibilidad y el profesionalismo que merecen las víctimas. 

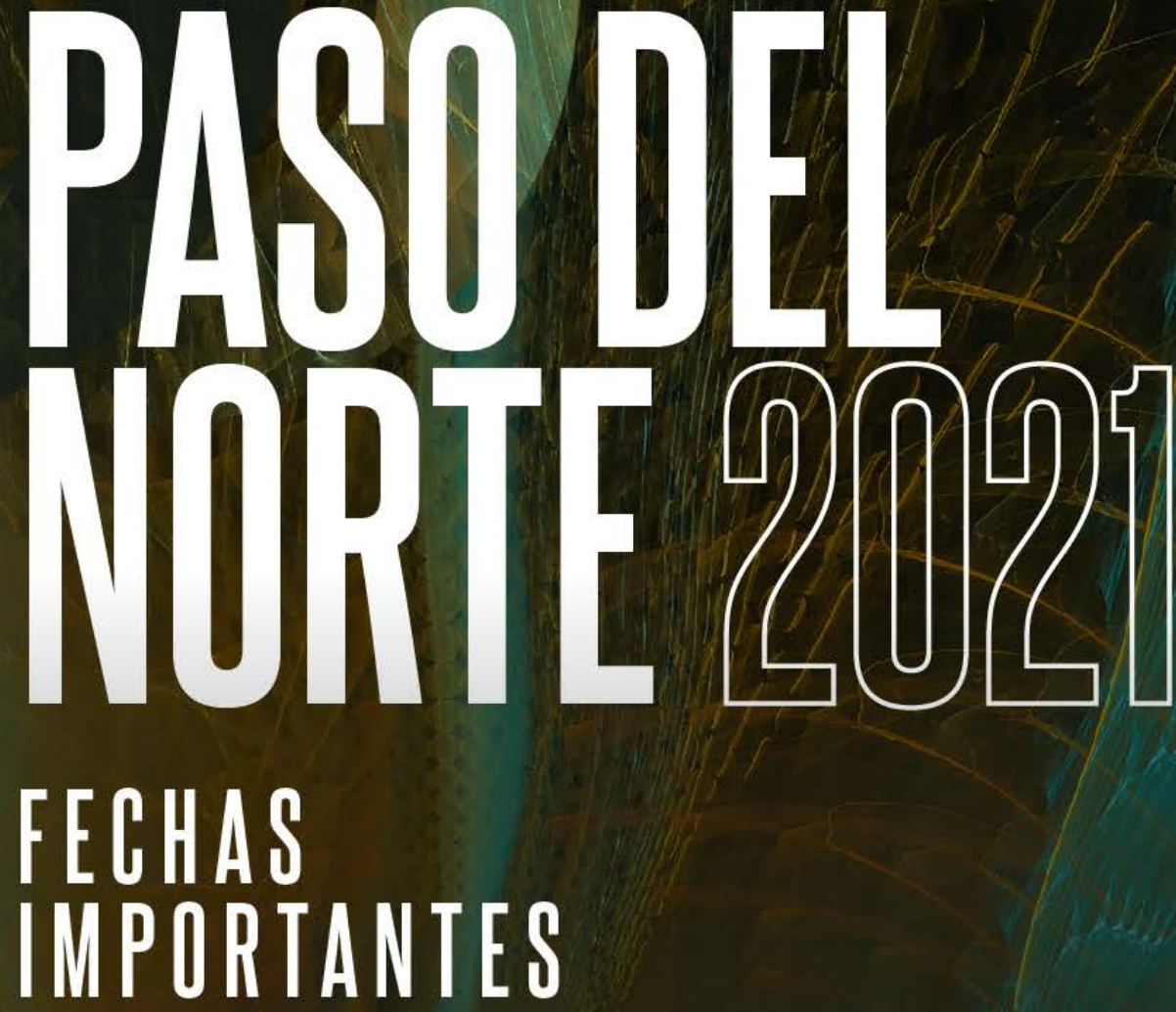

Recepción de trabajo

Del 15 de febrero al 7 de junio

Publicación de propuestas aceptadas 30 de julio

\begin{tabular}{ll}
\hline Fecha límite envío ponencias in extenso & $\mathbf{3 0}$ de septiembre \\
\hline Fecha límite de inscripción para ponentes & $\mathbf{8}$ de octubre \\
\hline Publicación del programa del Congreso & $\mathbf{2 2}$ de octubre \\
\hline Realización del Congreso & del $\mathbf{8}$ al $\mathbf{1 1}$ de noviembre \\
\hline Fecha límite para trámite de constancias & $\mathbf{3 0}$ de noviembre
\end{tabular}

Fecha límite para trámite de constancias

30 de noviembre

Registro de trabajos:

http://info.uacj.mx/congresocs2021 